\title{
Marine Biodiversity and the Medicine Cabinet The Status of New Drugs From Marine ORGANISMS
}

\author{
By William Fenical
}

$\mathrm{B}$ IODIVERSITY PROVIDEs the foundation in Nature for the production of diverse chemical compounds now used to treat human disease. Biodiversity translates to genetic uniqueness, which in turn results in the expression of diverse biochemical processes producing metabolic products which, in their natural settings. function mainly as defenses against predators. Natural substances used for defense have thus provided the foundation for the treatment of disease for over 3,000 years. Primitive societies, which interacted with their environments on a trial and error basis, recognized that plants contained "medicines" for a wide variety of maladies. This knowledge, often referred to as "ethnomedicine" was carefully documented and handed down through the centuries. Within the last 200 years, these curative, natural substances have been the focus of great interest leading ultimately to the development of the today's pharmaceutical industry.

There is no question that the development of drugs has greatly improved the quality and duration of human life. Substances such as morphine, quinine, penicillin, streptomycin, and digitalis, just to name a few, led to treatments and even complete cures for diseases that had once been considered fatal. The process of drug discovery continues today at a pace greater than ever before. And although sophisticated new approaches are applied, nature continues to provide the biochemical insight forming the foundation of

William Fenical, Scripps Institution of Oceanography. University of California-San Diego, La Jolla, CA 92093-10236. USA. many newly developed drugs. One example is the recently approved anticancer drug taxol, a compound extracted from the bark of the North American Yew tree. Taxol. perhaps by virtue of its unique mechanism of action, has shown excellent results in treating several forms of cancer that were previously difficult to treat.

As we move toward the 21 st century, there has never been a greater need for new drugs. The age demographics of society is changing to provide a focus on diseases, such as Alzheimers and arthritis. which create even greater threats to the quality of life. Heart disease continues as the major threat, while cures for cancer and AIDS continue to elude science. Unfortunately, many of the "wonder drugs" generated over the past several decades have become less useful due to the development of drug resistance. Many pathogenic bacteria, once susceptible to antibiotics, have developed sophisticated biochemical methods to escape the effects of these drugs. A strain of drug-resistant mycobacterium, the pathogen that causes tuberculosis, for example, is almost totally resistant to our arsenal of antibiotic drugs. Some infections are, today, produced by bacteria that are immune to all known antibiotics. Similarly, some forms of cancer have evolved multiple drug resistance, making virtually all drug treatments ineffective.

Despite advances in molecular biology and in computer-assisted drug design, Nature still provides the foundation for the discovery of new medically important compounds. Because of this, vigorous new programs such as the U.S. National Cancer Institute's (NCI) "Natural Product
National Cancer Drug Discovery Program" have established worldwide explorations. But unlike the past, these efforts have included the inhabitants of the world's oceans as a new source of biodiversity and novel drugs.

In contrast to the terrestrial environment, little ethnomedicinal information is available to guide current marine research. With the exception perhaps of southern China, few societies have used marine organisms as crude drugs. Thus studies now in progress have relied on ecological observations of chemical defense and survival to identify those organisms that might be expected to contain drug candidates. Pharmacological investigations of marine organisms are relatively new and have been founded on the establishment of unprecedented "scientific bridges" between the marine and pharmaceutical sciences. Today, approximately one-half of all cancer drug discovery focuses on marine organisms, and forecasts for the future are bright. In fact, some of the most important recent discoveries have been from the marine environment.

Marine drug discovery began in the late 1970 s by early investigators demonstrating, unequivocally, that marine plants and animals were genetically and biochemically unique (Fig. 1). Over 6,000 structurally unprecedented, and often highly bioactive metabolites have now been isolated from marine plants and animals. After the uniqueness of marine metabolism became accepted, programs began to evolve that linked academic marine scientists with biomedical researchers in the pharmaceutical industries. Programs, which established the foundations of today's efforts. were cre- 


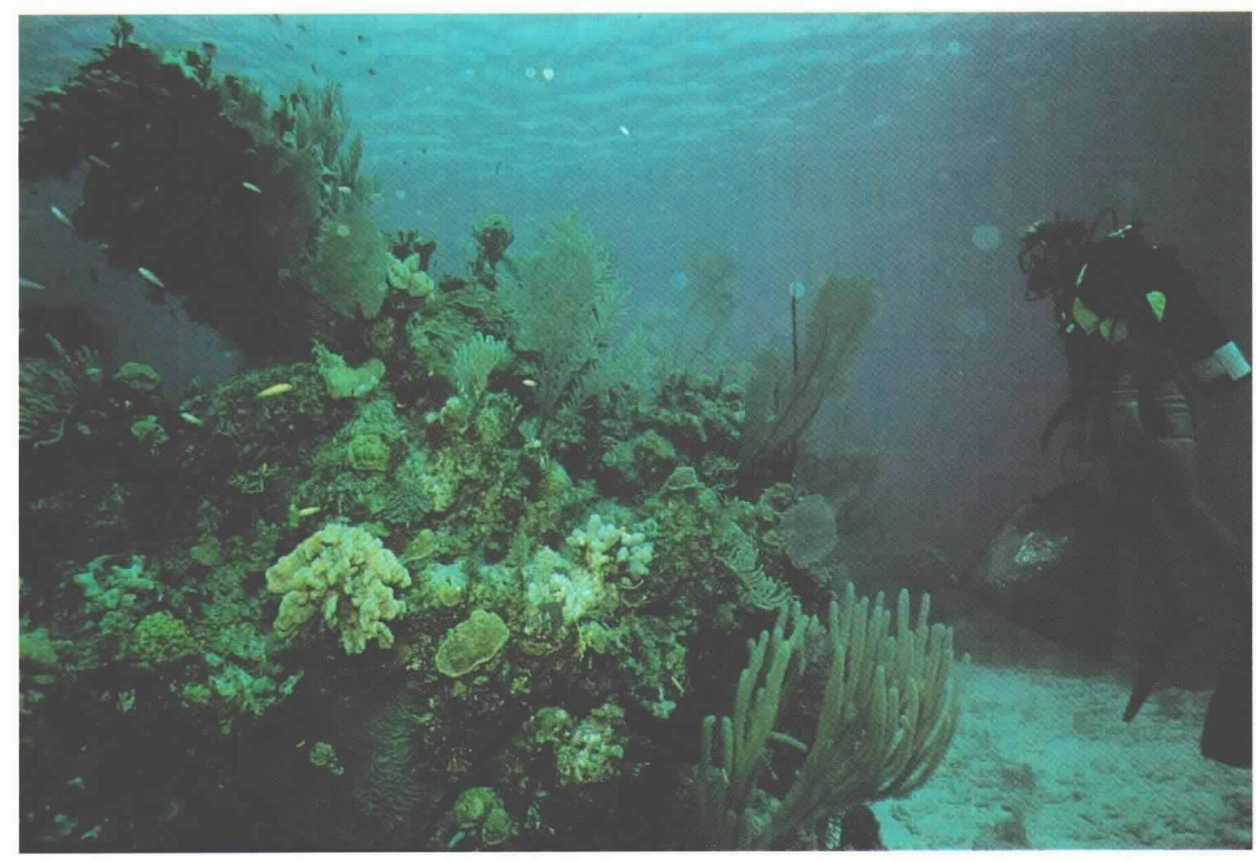

Fig. 1: Because competition for space and survival on coral reefs is so intense, organisms have developed significant levels of chemical defenses. These defenses provide the foundation for marine drug discovery.

ated in the 1980s in the United States, in Japan, and in Australia. Today these programs are expanding on the basis of their continuing discoveries of novel new drug leads.

Unlike the majority of terrestrial drug research, marine drug discovery programs have been applied to selected, difficult to treat diseases that have eluded cures for decades. Yet, progress has been observed in many of these difficult areas. New drug leads have been identified with potent immunosuppressant properties, with anti-inflammatory properties, and with significant anticancer potential. Although most of these compounds have not been suitable for drug development, they have already found utility as "pharmacological probes" providing selective pharmacological properties that can be used to explore the foundations of disease. A recent example of this is the sesterterpenoid, manoalide, isolated in Hawaii and California from the sponge Luffariella variabilis (de Silva and Scheuer, 1980; Potts et al., 1992). Manoalide was the first substance ever observed to selectively inhibit phospholipase $A_{2}$, an enzyme centrally involved in the inflammatory response. Although this compound ultimately failed as a drug, its use as a model for designing inhibitors of this important enzyme will have lasting effects in medical research. The same is bodied and vulnerable marine invertebrates. Perhaps the first molecule discovered was the unique cyclic ester bryostatin 1 (Fig. 2), isolated and defined by researchers at Arizona State University (Pettit et al., 1982). Bryostatin 1 occurs as a trace component of the common bryozoan Bugula neritina, which occurs worldwide often as a conspicuous component of the fouling communities on pier pilings. The molecule was recognized as a very potent inhibitor of numerous leukemia cells in culture. In fact, bryostatin 1 was the most selective antileukemia agent ever discovered. As is often the case, only selected populations of this well-known animal were found to contain bryostatin 1. This, coupled with the fact that bryostatin 1 comprises only approximately $1 \times 10^{-6} \%$ of the animal mass, created major problems in acquiring sufficient amounts of the compound to undertake advanced testing. The collections were accomplished, however, and although the results of clinical trials are not yet complete, there is no question that bryostatin 1 shows promise in the treatment of acute leukemia. Regardless of the results of these trials, it has already been acknowledged that bryostatin 1 is a chemically and pharmacologically unique substance of great interest in basic medical research. This compound possesses unprecedented immunostimulatory properties, and it activates protein kinase $\mathrm{C}$ (Suffness et al., 1989), an important regulator of hormone-mediated signal transduction, and a novel enzyme target for the development of new antitumor drugs.

In the 1970's, as part of an NCI-sponsored survey of Caribbean invertebrates, the impressive cytotoxic properties of extracts of the mangrove ascidian $E c$ teinascidia turbinata (Fig. 3) were discovered. Although it was clear, even then, that this animal contained substances of great potential importance, the great difficulty encountered in isolating and identifying the active substance(s) rendered this project virtually unsolvable. Here too, the active substances were present in vanishingly small amounts (1 $\times 10^{-4} \%$ ), and the compounds were apparently of a very new and difficult to isolate structural class. After 20 years of advancements in chemistry, the active substances, named the ecteinascidins, were isolated and described by researchers at the University of Illinois and the Harbor Branch Oceanographic Institution (Rinehart et al., 1990; Wright et 
New Marine Anticancer Drug Candidates

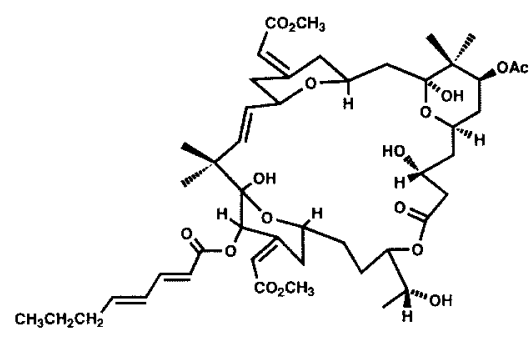

bryostatin 1

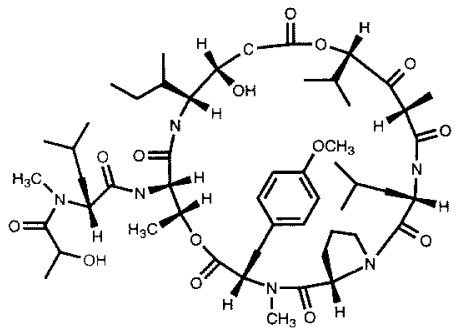

didemnin B

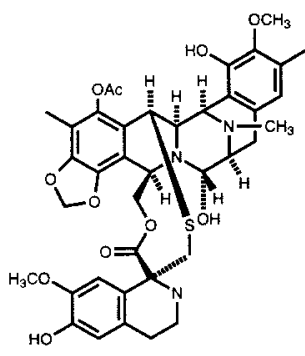

ecteinascidin $\mathbf{7 4 3}$

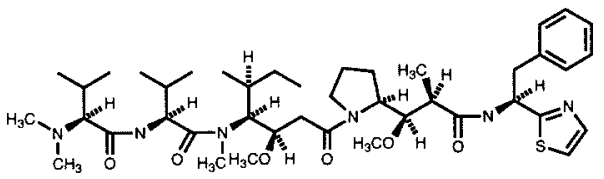

dolastatin 10

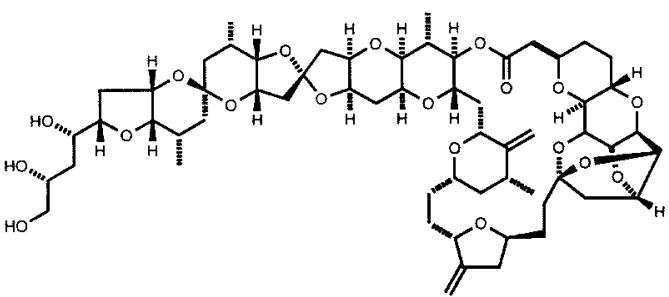

halıchondrın B

Fig. 2: New marine anticancer drug candidates.

al., 1990). The most abundant compound, ecteinascidin 743 (Fig. 2), showed excellent potency, $\mathrm{IC}_{50}=0.5 \mathrm{ng} / \mathrm{ml}$ against murine (L-1210) leukemia in vitro and significantly extended the life spans of mice infected with P-388 lymphocytic leukemia. In subsequent testing, this compound showed selectivity toward MXI human mammary tumors cultivated in mice. On the basis of these early studies, and more recent advanced preclinical investigations, ecteinascidin 743 will soon begin clinical trials in Europe. Unlike bryostatin 1, ecteinascidin 743 is chemically related to a rare group of $\mathrm{mi}-$ crobial antibiotics, the saframycins. tion of this animal was undertaken and larger amounts of didemnin B were isolated. Unfortunately. didemnin B has subsequently been found to exhibit significant toxicity at doses near those required for life extension. Although clinical trials of didemnin $B$ are not yet complete, this compound may be limited in its use. It is important to point out, however, that the evaluation of new drugs is a complex process in which both negative and positive results are continuously evaluated over time. Taxol, for example, required over 20 years of study before it was approved as a cancer drug.

A more recent addition to the list of exciting marine anticancer agents is dolastatin 10, a linear peptide discovered by researchers at Arizona State University (Pettit et al., 1987) from the sea hare Dolabella auricularia (Fig. 4), collected in the Indian Ocean. Found in complex mixtures with related peptides, dolastatin 10 showed outstanding inhihitory effects against several forms of skin cancers in laboratory studies. More importantly, subsequent whole animal testing showed this peptide to provide significant effects in controlling human B-16 and LOX melanoma in implanted mice. On the basis of these impressive properties, the NCI has been aggressive in advancing dolastatin 10 for clinical evaluation. Like the other molecules mentioned here, the results of clinical trials are not yet known. A curiosity of this work is the true origins of the peptides in $D$. auricularia. Sea hares are most often herbivores, and it has been unequivocally demonstrated that these shell-less mollusks acquire defensive chemicals from their diets rather than synthesizing them as many animals do. Thus dolastatin 10 and its relatives are most likely of an algal dietary origin. Based on our knowledge of the chemistry of marine algae. the dolastatins are likely to be produced by filamentous blue-green algae (cyanobacteria), which are often abundant in these habitats. The preferences of selected sea hares to consume blue-green algate has indeed been documented. But. to the best of my knowledge a dietary source for the dolastatins has not been identified.

Last. marine sponges have contributed the largest chemical diversity of all the marine invertebrates. Because most of these animals are soft-bodied and provide significant food for consumers, their re- 


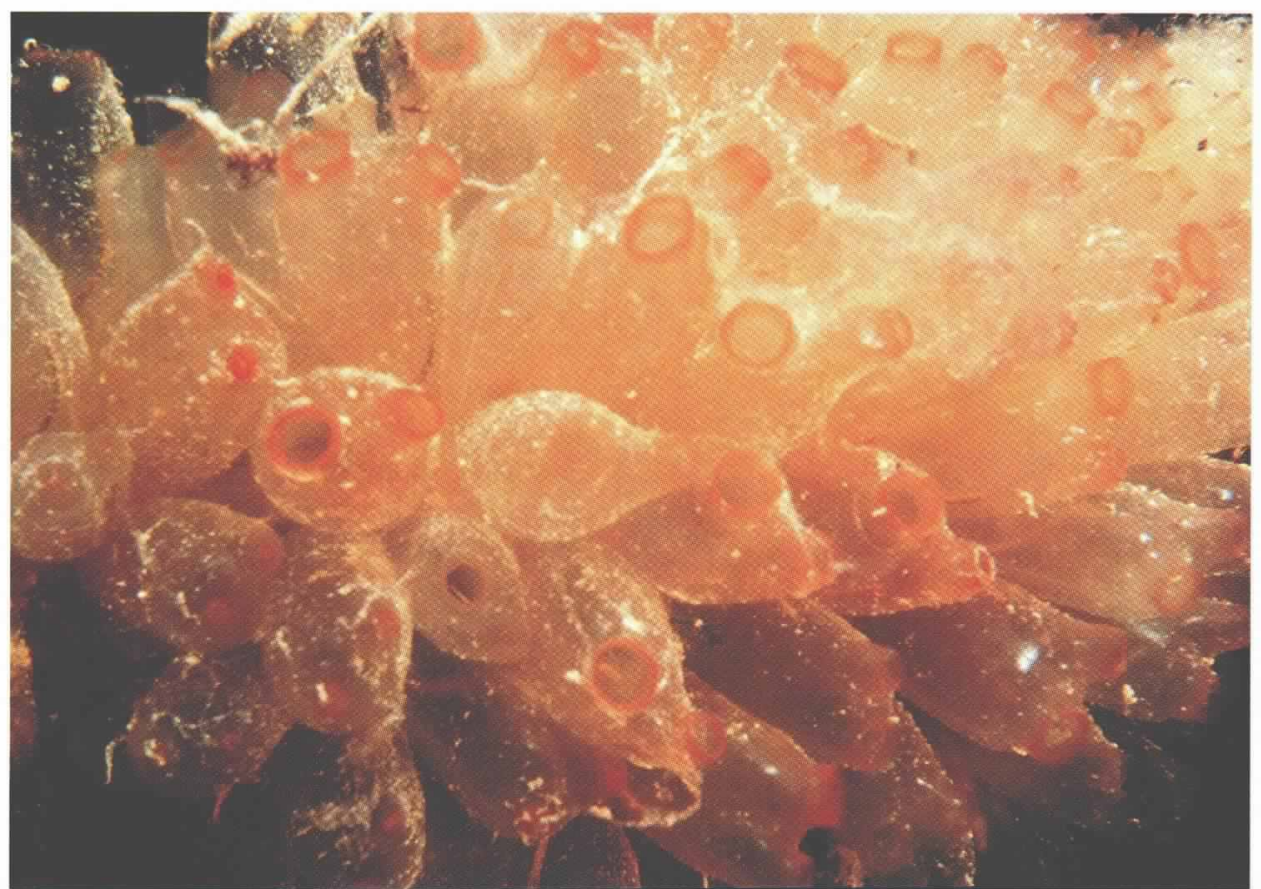

Fig. 3: A close-up view of the Caribbean mangrove ascidian Ecteinascidia turbinata. This animal contains the ecteinascidins, a new class of anticancer agents about to be evaluated in human clinical trials.

liance on chemical defenses has been clear. Many of these compounds have possessed important biomedical properties, but only recently was a sponge-derived compound, halichondrin $\mathrm{B}$, added to the list of agents to enter clinical trials. Halichondrin B, a novel polyether, was

isolated and first identified in Japan (Hirata and Uemura, 1986). This interesting metabolite was discovered in the sponge Halichondria okadai (Fig. 5), various collections of which have yielded a variety of diverse toxins. Halichondrin B (Fig. 2) is a novel compound, related most closely

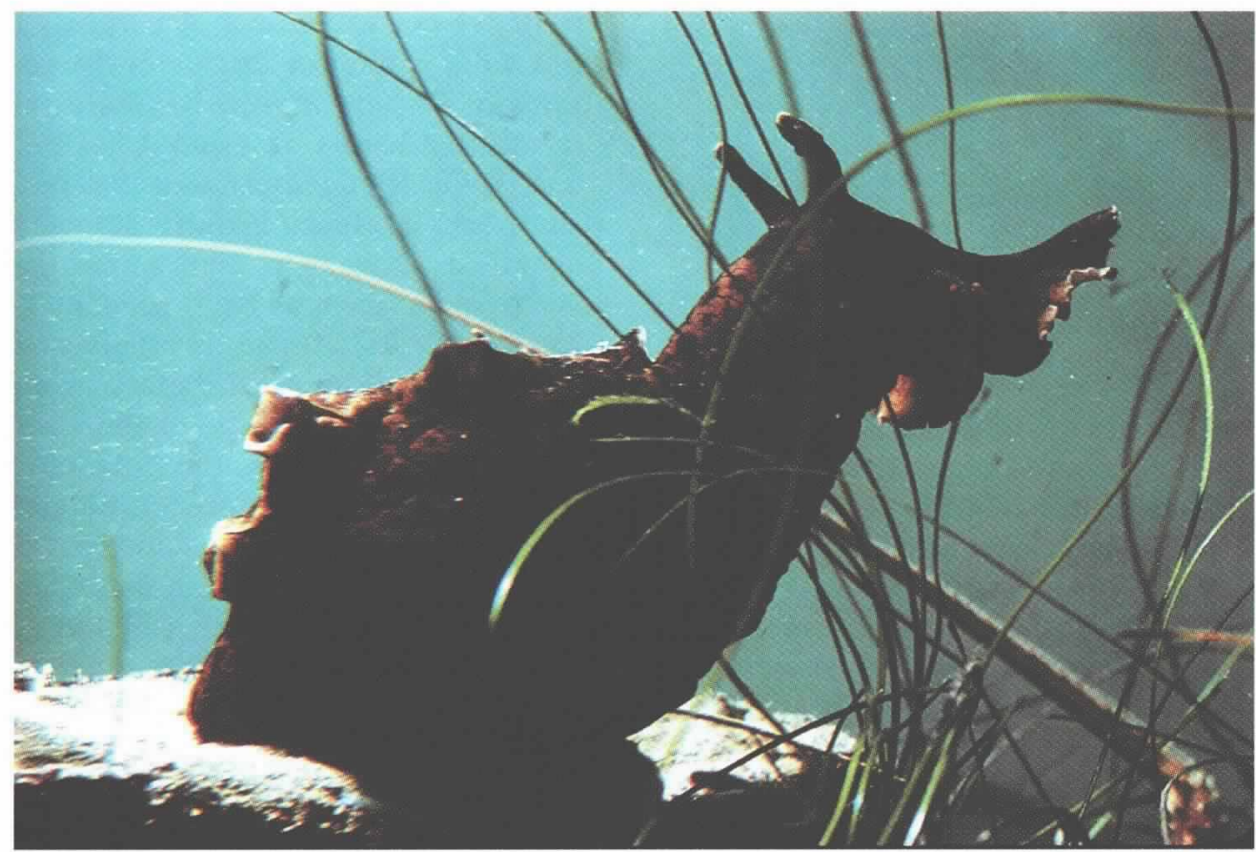

Fig. 4: The sea hares are shell-less mollusks that accumulate defensive substances from their largely algal diets. Sea hares have been extensively chemically studied, and one species, Dolabella auricularia, has yielded a potent new anticancer drug candidate. to several of the toxins produced by toxigenic dinoflagellates. Because of this relationship, and because $H$. okadai had been found to concentrate okadaic acid, a metabolite of the dinoflagellate Prorocentrum lima mentioned earlier, it seems logical that the compound may also be of dinoflagellate origin probably acquired by the filter feeding process. Supporting this concept, halichondrin $\mathrm{B}$ has recently been isolated by several investigators from a variety of sponges. Because this is the most recent addition to the list of marine drugs undergoing clinical trials, little data are available to predict success. Halichondrin B shows selective antitumor effects against human ovarian cancers in mice, as well as activity against melanoma and various forms of leukemia. It seems clear that Halichondrin $\mathrm{B}$ is one of the most promising new anticancer drug isolated to date.

In discussions of marine drugs, it is important to distinguish between molecules providing "drug leads" and those molecules more adequately described as "drug candidates" that are presented here. Marine plants and animals have provided literally hundreds of compounds that can be defined as the former, but few have advanced to the stages of clinical trials. The molecules presented here are thus concrete examples of the exciting advances being made in marine drug discovery.

The approach of this article is not meant to minimize the importance of the numerous marine drug leads that are still in early stages of preclinical evaluation. To the contrary, my knowledge of these compounds suggests that they have already contributed significantly to biomedical research and may indeed reach the status of clinical trials. Recent examples of molecules being intensely studied are discodermolide, a unique immunosuppressive and cytotoxic agent, isolated by Harbor Branch Oceanographic Institution scientists from the deep water sponge Discodermia dissoluta (Gunasekera et al., 1990), and curacin, a novel anticancer agent from the Caribbean bluegreen alga Lyngbya majuscula, recently discovered by researchers at Oregon State University (Gerwick et al., 1994). Discodermolide has recently been shown to possess the identical tubulin polymer stabilizing properties as taxol, (ter Haar et al., 1996) which certainly indicates that comprehensive preclinical studies should be undertaken. In other therapeutic areas, several molecules have shown significant promise in the treatment of inflammation and pain. 


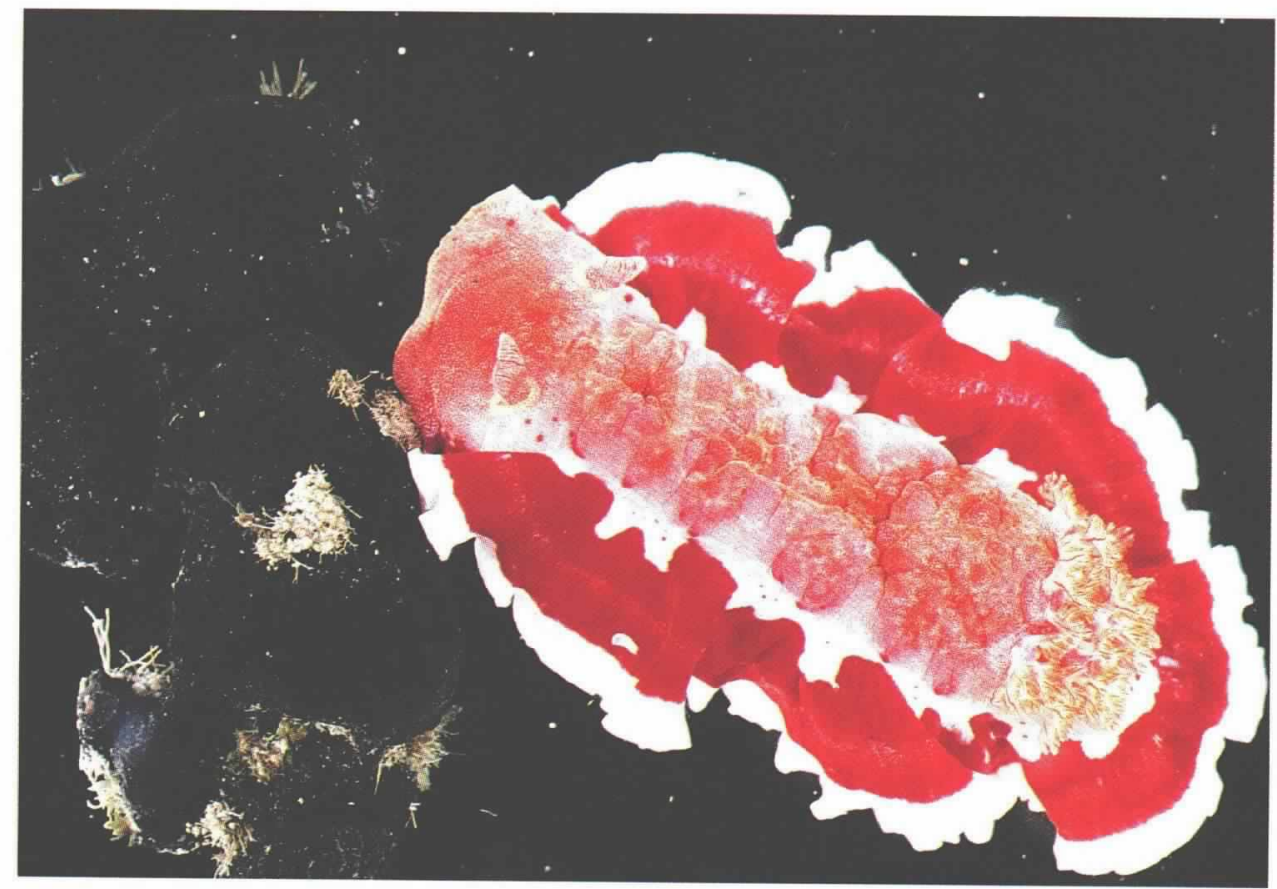

Fig. 5: Like the sea hares, the "Spanish Dancer" nudibranch Hexabranchus sanguineus acquires defensive compounds from its food source, the sponge Halichondria sp. As exemplified in the case of halichondrin B, Halichiondria species contain unique, bioactive metabolites.

The pseudopterosins, isolated from the Caribbean sea whip Pseudopterogorgia elisabethae by Scripps Institution of Oceanography scientists (Look et al., 1986), show impressive anti-inflammatory properties in several skin models (see Hay and Fenical, 1996, this issue). Studies of the pseudopterosins have progressed to the point in which clinical trials, which may ultimately focus on arthritis and other debilitating inflammatory diseases, are about to begin.

The history of research support in the United States has involved the National Institutes of Health and in a more fundamental way, the NOAA, Sea Grant Program. While NIH support has been more recent and focused, and obviously responsible for the development of the anticancer drugs mentioned here, Sea Grant should be credited for providing the foundation of this work. Beginning in the early 1980s, when exploration for marine bioactive substances were premature and unrefined, the Sea Grant Program invested in the long-term development of this field. The successes we now enjoy can be credited to both the National and State Sea Grant Programs for their insight and commitment in establishing this important area.

What is the future of marine drug research? Clearly this requires gazing into a crystal ball. What appears likely is that studies of new drug leads from marine sources will significantly expand. As the scientific bridges between marine science and drug discovery continue to be built, new and enlarged collaborations will lead to expanded pharmacological research. There is no doubt that these studies will identify novel marine drug candidates in diverse areas of therapeutic development. When one considers the scope of marine biodiversity, including such major, uninvestigated groups as marine bacteria and fungi, it seems likely that marine sources could be the major source of new drugs for the next decade.

\section{References}

de Silva, E.D. and P.J. Scheuer, 1980: Manoalide, an antibiotic sesterterpenoid from the marine sponge Luffariella variabilis. Tetrahedron Lett., 21, 1611-1614.

Gerwick, W.H., P.J. Proteau, D.G. Nagle, E. Hamel, A. Blotchin and D.L. Slate, 1994: Structure of curacin A, a novel antimitotic, antiproliferative, and brine shrimp toxic natural product from the marine cyanobacterium Lyngbya majuscula. J. Org. Chem., 59, 1243-1245.

Gunasekera, S.P., M. Gunasekera and G.K. Schulte, 1990: Discodermolide: a new bioactive polyhydroxylated lactone from the marine sponge Discodermia dissoluta. J. Org. Chem., 55, 4912-4915. erratum. 1991. J. Org. Chem., 56, 1346.

Hay, M.E. and W. Fenical, 1996: Chemical ecology and marine biodiversity: insights and products from the sea. Oceanography, 9, 10-20.

Hirata, Y. and D. Uemura, 1986: Halichondrinsantitumor polyether macrolides from a marine sponge. Pure Appl. Chem., 58, 701-710,

Look, S.A., W. Fenical, R.S. Jacobs and J. Clardy, 1986: The pseudopterosins; antiinflammatory and analgesic natural products from sea whip Psendopterogorgia elisabethae. Proc. Natl. Acad. Sci. USA. 83, 6238-6240.

Pettit, G.R., C.L. Herald, D.L. Doubek, D.L. Herald, E. Arnold and J. Clardy, 1982: Isolation and structure of bryostatin 1.J. Am. Chem. Soc., 104, 6846-6848.

, Y. Kamano, C.L. Herald, A.A. Tuinman, F.E. Boettner, H. Kizu, J.M. Schmidt, L. Baczynskyj, K.B. Tomer and R.J. Bontems, 1987: Isolation and structure of a remarkable marine animal antineoplastic constituent: dolastatin 10. J. Am. Chem. Soc., 109, 6883-6885.

Potts, B.C.M., D.J. Faulkner, M.S. de Carvalho and R.S. Jacobs, 1992: Chemical mechanism of inactivation of bee venom phospholipase $\mathrm{A}_{2}$ by the natural products manoalide, luffariellolide and scalaradiol. J. Am. Chem. Soc., $114,5093-5101$

Rinehart, K.L., Jr., J.B. Gloer, J.C. Cook, S.A. Mizsak and T.A. Scahill, 1981: Structures of the didemnins; antiviral and cytotoxic depsipeptides from a Caribbean tunicate. $J . \mathrm{Am}$. Chem. Soc., 103, 1857-1859.

T.G. Holt, N.L. Fregeau, J.G. Stroh, P.A. Keifer, F. Sun, L.H. Li and D.G. Martin, 1990: Ecteinascidins 729, 743. 745, 759A, 759B, and 770: potent antitumor agents from the Caribbean tunicate Ecteinascidia turbinata. J. Org. Chem. 55, 4512-4515.

Suffness, M., D.J. Newmann and K. Snader, 1989 Discovery and development of antineoplastic agents from natural sources. In: Bioorganic Chemistry, vol. 3. P.J. Scheuer, ed. Springer-Verlag, New York, 131-168.

ter Haar, E., R.J. Kowalski, E. Hamel, C.M. Lin. R.E. Longley, S. Gunasekera, H.S. Rosenkranz and B.W. Day, 1996: Discodermolide, a cytotoxic marine agent that stabilizes microtubules more potently than taxol. Biochemistry, 35, 243-245.

Wright, A.E., D.A. Forleo, G.P. Gunawardana, S.P. Gunasekera, F.E. Koehn and O.J. McConnell, 1990: Antitumor tetrahydroisoquinoline alkaloids from the colonial ascidian Ecteinascidia turbinata. J. Org. Chem., $55,4508-4512$. 